\title{
Trends in sexual behaviour and HIV testing among women presenting at a genitourinary medicine clinic during the advent of AIDS
}

\author{
Brian A Evans, Sheena M McCormack, Robert A Bond, Kenneth D MacRae
}

\begin{abstract}
Changes in female sexual behaviour with the advent of AIDS and safer sex campaigns were studied. Subjects were drawn from a wide social spectrum of women attending an STD clinic in West London where there is a high prevalence of HIV infection among homosexual men. Between 1982 and 1989, 4224 women answered a self-administered questionnaire: women who reported more than one sexual partner in the previous year fell from $56.9 \%$ in 1982 to $51.8 \%$ in $1989(p=0.003)$. Anal intercourse showed no change and was reported by $8 \cdot 8 \%$ in 1982 and $9 \cdot 4 \%$ in $1989(p=0.8)$. Oral intercourse increased from $36.9 \%$ in 1982 to $44.7 \%$ in $1989(p=0.001)$. Condom use for contraception increased from $3.6 \%$ in 1982 to $16.2 \%$ in $1989(p<0.001)$. Between 1987 and $1989,35.6 \%$ of 3199 women reported having non-regular partners with no significant trend over this period; these women had earlier coitarche (17.0 years cf 17.9 years), many more partners $(p<0.0001)$ and more practised anal $(p=0.007)$ and oral $(p<0.0001)$ intercourse. However, frequent use of condoms doubled from $23.6 \%$ in 1987 to $47.6 \%$ in 1989 . During this period, the prevalence of antibody to HIV (anti-HIV) remained unchanged $(0 \cdot 27-0 \cdot 37 \%)$, but more women declined to be tested. Anonymised testing showed that none of those who refused consent for named testing was anti-HIV positive.

It is concluded that significant changes in female sexual behaviour have taken place with the advent of AIDS but there has been no evidence of heterosexual spread beyond the confines of well defined risk behaviours. Risks of the magnitude reported in homosexual men were not found in heterosexual women.
\end{abstract}

Department of Genitourinary Medicine, Charing Cross Hospital, London W6 8RF

Brian A Evans, Sheena M McCormack

Charing Cross and Westminster Medical School, Charing Cross Hospital

Robert A Bond, Kenneth D MacRae

\section{Introduction}

Human Immunodeficiency Virus (HIV) has so far spread largely among homosexual men and intravenous drug users in temperate climates and heterosexually in tropical climates. The potential for heterosexual spread in temperate climates is therefore a matter of great concern.

Despite the increasing prevalence of HIV infection, little is known about the effect of campaigns advocating safer sex. DeBuono et al ${ }^{1}$ found little change between 1975 and 1989 in the sexual practices of college women attending a large private university in Northeast USA, apart from an increase in the use of condoms.

We have looked at women attending a genitourinary medicine clinic for sexually transmitted diseases (STDs) in the Riverside Health District of West London, which has the largest caseload of HIV infection in the United Kingdom and thus constitutes a key sentinel population for monitoring heterosexual spread. Our study began in 1982 with the aim of assessing female sexual behaviour every five years. However, the advent of HIV infection necessitated two modifications to the study design. The first was to incorporate data related to HIV infection and the effect of subsequent health education campaigns and the second was to carry out the study annually rather than every five years.

Patients and methods

The protocol for these studies has been described previously. ${ }^{23}$ Briefly, consecutive patients newly attending the Genitourinary Medicine Clinic at West London Hospital in 1982, 1987, 1988 and 1989 received a self-administered questionnaire on sexual behaviour to which specific questions about condom use with regular and non-regular partners were added from $1987 .{ }^{3}$ This left the individual patient to judge whether her sexual partners were regular or non-regular and to omit the latter if not applicable. Data on age, contraception and pregnancy were collected from the clinical records. Studies were terminated after the recruitment of approximately 1200 patients. Only fully completed questionnaires were analysed. 
All patients were screened for anti-HIV antibodies in 1987. In subsequent years, patients were offered this test, which was then carried out after appropriate counselling and informed consent. Residual sera from those who declined named testing for anti-HIV were collected, stored until completion of the study, unlinked and tested as a batch of anonymous samples. ${ }^{45}$ The study was approved by the hospital's Ethical Sub-Committee.

Sera were tested for anti-HIV by COMPRIA as previously described. ${ }^{6}$ Data were analysed on the University of London's Amdahl computer system using the SPSS-X package. Statistical analysis utilised Students' $t$ test, the chi square test and the chi square test for trend. The trend analysis was amended to take account of the irregular time spacing between surveys. ${ }^{7}$

\section{Results}

Patients who completed the questionnaire on sexual behaviour in the years 1982 and $1987 / 89$ (table 1) numbered 4224, and $125(3 \%)$ refused to complete it. Ages ranged from 14 to 75 years (mean 25.8 years); $3979(94 \cdot 2 \%)$ were under 40 years of age. The proportion of teenagers declined considerably ( $p<$ $0.001)$. There were $3358(79.5 \%)$ single women, 498 $(11.8 \%)$ married women and $363(8.6 \%)$ separated, divorced or widowed. Here the most marked changes were a decrease in women who were separated or divorced $(p=0.01)$ and an increase in single women $(p=0.003)$.

Trends in sexual behaviour 1982-1989

Trends in age and current contraception are shown in table 1 . Mean age (range: $25 \cdot 6-26 \cdot 2$ years) and non-use of contraception (range: $24.5 \%-25.9 \%$ ) remained unchanged but there was a significant downtrend in use of oral contraception and the IUCD ( $p<0.001)$. By contrast, condom use showed a considerable uptrend from $3 \cdot 6 \%$ to $16 \cdot 2 \%$ $(\mathrm{p}<0.001)$.

Numbers of sexual partners in the preceding year (table 2) showed a consistent downtrend for more than one $(p=0.003)$, more than two $(p<0.001)$ and more than five partners $(p<0.001)$. The only significant trend in respect of lifetime number of partners was in women reporting more than $50(\mathrm{p}=$ 0.008 ).

Anal intercourse showed a downward trend for penetration over the seven year time span $(p=0.024)$ and oral intercourse increased significantly, both for penetration $(p=0.001)$ and ejaculation $(p=0.001)$. Full anal intercourse with ejaculation remained unchanged $(\mathrm{p}=0 \cdot 79)$.

Use of condoms with both regular and non-regular partners showed a highly significant uptrend between 1987 and 1989 (table 3 ). Whereas $53.1 \%$ never used condoms with non-regular partners in 1987, this had fallen to $29.9 \%$ in 1989 . Frequent use of condoms (often or always) doubled from $23.6 \%$ to $47.6 \%$ over the same period. The proportion of women having non-regular partners, however, did not change.

\section{Patients with non-regular sexual partners}

Of the 3119 patients questioned between 1987 and $1989,1139(35.6 \%)$ responded to the question on condom use with non-regular partners. This subgroup showed a markedly different sexual behaviour pattern from those who did not respond to this question (table 4). Mean age and coitarche were both approximately one year younger. Numbers of partners were substantially more, both in the last year and

Table 1 Age and marital status and contraception

\begin{tabular}{|c|c|c|c|c|c|}
\hline \multirow[b]{2}{*}{ Variables } & \multicolumn{4}{|l|}{ Study years } & \multirow{2}{*}{$\underset{p}{\chi^{2}}$ for trend } \\
\hline & $1982(n=1025)$ & $1987(n=1079)$ & $1988(n=1073)$ & $1989(n=1047)$ & \\
\hline Refusal to complete & 18 & 33 & 35 & 39 & 0.006 \\
\hline $\begin{array}{l}\text { Mean } \\
\text { Range } \\
\text { Below } 20 \\
\text { Below } 30\end{array}$ & $\begin{array}{l}25 \cdot 6 \\
14-61 \\
193 \quad(18 \cdot 8 \%) \\
792 \quad(77 \cdot 3 \%)\end{array}$ & $\begin{array}{l}25 \cdot 8 \\
15-64 \\
165 \quad(15 \cdot 3 \%) \\
841 \quad(77 \cdot 9 \%)\end{array}$ & $\begin{array}{l}26 \cdot 2 \\
14-70 \\
121 \quad(11 \cdot 3 \%) \\
822 \quad(76 \cdot 6 \%)\end{array}$ & $\begin{array}{l}25 \cdot 8 \\
14-66 \\
146 \quad(13 \cdot 9 \%) \\
821 \quad(78 \cdot 4 \%)\end{array}$ & $\begin{array}{c}- \\
<0.001 \\
0.76\end{array}$ \\
\hline $\begin{array}{l}\text { Marital status } \\
\text { Single } \\
\text { Married } \\
\text { Separated/divorced } \\
\text { Widowed }\end{array}$ & $\begin{aligned} &(n=1025) \\
& 784(76.5 \%) \\
& 134(13 \cdot 1 \%) \\
& 101(9.9 \%) \\
& 6(0.6 \%)\end{aligned}$ & $\begin{aligned}(\mathrm{n}= & 1076) \\
857 & (79 \cdot 6 \%) \\
120 & (11 \cdot 2 \%) \\
92 & (8.6 \%) \\
6 & (0.6 \%)\end{aligned}$ & $\begin{aligned} &(n=1073) \\
& 860(80 \cdot 1 \%) \\
& 130(12 \cdot 1 \%) \\
& 78(7 \cdot 3 \%) \\
& 5(0.5 \%)\end{aligned}$ & $\begin{aligned}(\mathrm{n}= & 1046) \\
857 & (81.9 \%) \\
114 & (10.9 \%) \\
73 & (7 \cdot 0 \%) \\
2 & (0.2 \%)\end{aligned}$ & $\begin{array}{l}0.003 \\
0.15 \\
0.01 \\
0.30\end{array}$ \\
\hline $\begin{array}{l}\text { Contraception } \\
\text { None } \\
\text { Pill } \\
\text { IUCD } \\
\text { Condom } \\
\text { Cap } \\
\text { Other }\end{array}$ & $\begin{aligned} &(\mathrm{n}=1025) \\
& 253(24 \cdot 7 \%) \\
& 525(51 \cdot 2 \%) \\
& 107(10 \cdot 4 \%) \\
& 37(3 \cdot 6 \%) \\
& 58(5 \cdot 7 \%) \\
& 48(4 \cdot 4 \%)\end{aligned}$ & $\begin{aligned}(\mathrm{n}= & 992) \\
243 & (24 \cdot 5 \%) \\
464 & (46.8 \%) \\
68 & (6 \cdot 9 \%) \\
101 & (10 \cdot 2 \%) \\
69 & (7 \cdot 0 \%) \\
47 & (4 \cdot 7 \%)\end{aligned}$ & \begin{aligned} & \multicolumn{2}{c}{$(\mathrm{n}=1046)$} \\
& 271$(25 \cdot 9 \%) \\
& 470(44 \cdot 9 \%) \\
& 57(5 \cdot 4 \%) \\
& 131(12 \cdot 5 \%) \\
& 61(5 \cdot 8 \%) \\
& 56(5 \cdot 4 \%)\end{aligned}$ & \begin{aligned} & \multicolumn{2}{c}{$(\mathrm{n}=1020)$} \\
& 258$(25 \cdot 3 \%) \\
& 434(42 \cdot 5 \%) \\
& 46(4 \cdot 5 \%) \\
& 165(16 \cdot 2 \%) \\
& 59(5 \cdot 8 \%) \\
& 58(5 \cdot 7 \%)\end{aligned}$ & $\begin{array}{l}0.65 \\
<0.001 \\
<0.001 \\
<0.001 \\
0.76 \\
0.34\end{array}$ \\
\hline
\end{tabular}


Table 2 Partners and practices

\begin{tabular}{|c|c|c|c|c|c|c|c|c|c|c|}
\hline \multirow[b]{2}{*}{ Variable } & & \multicolumn{8}{|c|}{ Study years } & \multirow{2}{*}{$\chi_{p}^{2}$ for trend } \\
\hline & & \multicolumn{2}{|c|}{$1982(n=1025)$} & \multicolumn{2}{|c|}{$1987(n=1079)$} & \multicolumn{2}{|c|}{$1988(n=1073)$} & \multicolumn{2}{|c|}{$1989(n=1047)$} & \\
\hline $\begin{array}{c}\text { Anal intercour } \\
\text { Penetration } \\
\text { Ejaculation }\end{array}$ & & $\begin{array}{r}200 \\
90\end{array}$ & $\begin{array}{l}(19 \cdot 5 \%) \\
(8 \cdot 8 \%)\end{array}$ & $\begin{array}{r}164 \\
88\end{array}$ & $\begin{array}{l}(15 \cdot 2 \%) \\
(8 \cdot 2 \%)\end{array}$ & $\begin{array}{r}165 \\
95\end{array}$ & $\begin{array}{l}(15 \cdot 5 \%) \\
(8 \cdot 9 \%)\end{array}$ & $\begin{array}{r}180 \\
98\end{array}$ & $\begin{array}{l}(17 \cdot 1 \%) \\
(9 \cdot 4 \%)\end{array}$ & $\begin{array}{l}0.024 \\
0 \cdot 79\end{array}$ \\
\hline
\end{tabular}

Table 3 Condom use with regular and non-regular sexual partners

\begin{tabular}{|c|c|c|c|c|}
\hline \multirow[b]{2}{*}{ Condom use } & \multicolumn{3}{|l|}{ Study years } & \multirow{2}{*}{$\chi_{p}^{2}$ for trend } \\
\hline & 1987 & 1988 & 1989 & \\
\hline $\begin{array}{l}\text { Regular partners } \\
\text { Never } \\
\text { Occasionally } \\
\text { Often/always }\end{array}$ & $\begin{array}{ll}\mathrm{n}= & 1066 \\
672 & (63 \cdot 0 \%) \\
262 & (24 \cdot 6 \%) \\
132 & (12 \cdot 4 \%)\end{array}$ & $\begin{array}{ll}\mathrm{n}= & 1038 \\
546 & (52 \cdot 6 \%) \\
327 & (31 \cdot 5 \%) \\
165 & (15 \cdot 9 \%)\end{array}$ & $\begin{array}{ll}\mathrm{n}=1015 \\
490 & (48 \cdot 3 \%) \\
317 & (31 \cdot 2 \%) \\
208 & (20 \cdot 5 \%)\end{array}$ & $<0.001$ \\
\hline $\begin{array}{l}\text { Non-regular partners } \\
\text { Never } \\
\text { Occasionally } \\
\text { Often/always }\end{array}$ & $\begin{aligned} \mathrm{n}= & 424 \\
225 & (53 \cdot 1 \%) \\
99 & (23 \cdot 3 \%) \\
100 & (23 \cdot 6 \%)\end{aligned}$ & \begin{aligned} & \multicolumn{2}{c}{$\mathrm{n}=347$} \\
& 158$(45 \cdot 5 \%) \\
& 78(22 \cdot 5 \%) \\
& 111(32 \cdot 0 \%)\end{aligned}$ & \begin{aligned} & \multicolumn{2}{c}{$\mathrm{n}=368$} \\
& 110$(29 \cdot 9 \%) \\
& 83(22 \cdot 5 \%) \\
& 175(47 \cdot 6 \%)\end{aligned}$ & $\begin{array}{r}0.09 \\
<0.001\end{array}$ \\
\hline
\end{tabular}

Table 4 Characteristics of patients with regular and non-regular sexual partners

\begin{tabular}{|c|c|c|c|}
\hline \multirow[b]{2}{*}{ Variables } & \multicolumn{2}{|l|}{ Sexual partners } & \multirow[b]{2}{*}{$p$} \\
\hline & No non-regular $(n=2060)$ & Non-regular $(n=1139)$ & \\
\hline $\begin{array}{l}\text { Age (mean years) } \\
\text { Menarche (mean years) } \\
\text { Coitarche (mean years) } \\
\text { Never pregnant } \\
\text { Partners in last year: }\end{array}$ & $\begin{array}{l}26 \cdot 25 \\
13 \cdot 05 \\
17 \cdot 91 \\
1162(1976) \quad(58 \cdot 8 \%)\end{array}$ & $\begin{array}{l}25 \cdot 34 \\
13 \cdot 16 \\
16 \cdot 99 \\
668 \quad(1067) \quad(62 \cdot 6 \%)\end{array}$ & $\begin{aligned}<0.001^{\star} \\
0.054^{\star} \\
<0.001^{\star} \\
0.04 \dagger^{\star}\end{aligned}$ \\
\hline $\begin{array}{l}\quad>1 \\
>2 \\
>5 \\
\text { Partners in lifetime: }\end{array}$ & $\begin{aligned} 555 & (26.9 \%) \\
166 & (8 \cdot 1 \%) \\
12 & (0 \cdot 6 \%)\end{aligned}$ & $\begin{aligned} 1107 & (97 \cdot 2 \%) \\
614 & (53.9 \%) \\
99 & (8 \cdot 7 \%)\end{aligned}$ & $\begin{array}{l}<0.0001 \dagger \\
<0.0001 \dagger \\
<0.0001 \dagger\end{array}$ \\
\hline $\begin{array}{l}>5 \\
>10 \\
\text { Anal intercourse: }\end{array}$ & $\begin{array}{ll}721 & (35.0 \%) \\
256 & (12.4 \%)\end{array}$ & $\begin{array}{ll}802 & (70 \cdot 4 \%) \\
419 & (36 \cdot 8 \%)\end{array}$ & $\begin{array}{l}<0.0001 \dagger \\
<0.0001 \dagger\end{array}$ \\
\hline $\begin{array}{l}\text { Penetration } \\
\text { Ejaculation } \\
\text { Oral intercourse: }\end{array}$ & $\begin{array}{ll}277 & (13 \cdot 4 \%) \\
160 & (7 \cdot 8 \%)\end{array}$ & $\begin{array}{ll}232 & (20 \cdot 4 \%) \\
121 & (10 \cdot 6 \%)\end{array}$ & $\begin{array}{c}<0.0001 \dagger \\
0.007 \dagger\end{array}$ \\
\hline $\begin{array}{l}\text { Penetration } \\
\text { Ejaculation } \\
\text { Condoms used with regular partner }\end{array}$ & $\begin{aligned} 1454 & (70 \cdot 6 \%) \\
765 & (37 \cdot 1 \%) \\
953 & (2010)(47 \cdot 4 \%)\end{aligned}$ & $\begin{array}{ll}960 & (84 \cdot 3 \%) \\
587 & (51 \cdot 5 \%) \\
458 & (1109)(41 \cdot 3 \%)\end{array}$ & $\begin{array}{l}<0.0001 \dagger \\
<0.0001 \dagger \\
0.001 \dagger\end{array}$ \\
\hline
\end{tabular}

$\star$ Student's $t$ test. †Chi square test. 
Table 5 HIV infection and risk factors

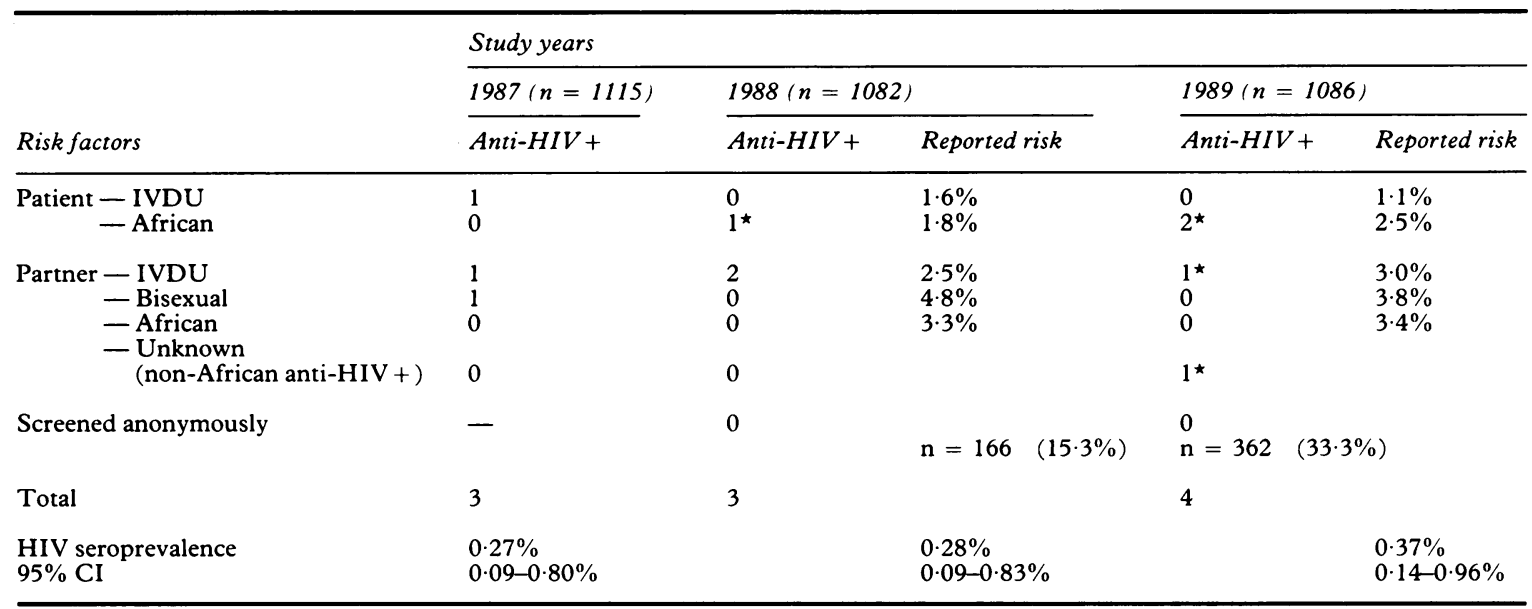

^Non-UK born.

in total throughout the range of partners. Anal and oral intercourse were practised more frequently and condoms were used with regular partners less frequently. Menarche occurred later but this did not reach significance by the chi square test. However, significantly fewer women in this multiple partner group had become pregnant although their contraceptive practice did not differ.

\section{HIV infection and risk}

The outcome of HIV testing between 1987 and 1989 is tabulated by risk category in table 5 . In 1988 and 1989 , patients were asked specifically about risks in a parallel questionnaire linked to testing for HIV infection. There was no change in prevalence during the three years $(0 \cdot 27-0.37 \%)$. In 1987 , all patients were screened as reported previously. In the next two years, testing was primarily with informed consent. The untested sera were batched, unlinked from their source and then tested anonymously. The number of patients who declined named testing more than doubled from 166 sera $(15.3 \%$ ) in 1988 to $362 \mathrm{~m}$ sera $(33.3 \%)$ in 1989; none of them was anti-HIV positive. Five of the 10 patients who tested positive were born outside the United Kingdom.

\section{Discussion}

This study of sexual activity in active women attending a genitourinary medicine clinic in London between 1982 and 1989 has shown that significant changes have taken place. Fewer teenagers and separated or divorced women attended as the study progressed. These groups may be more responsive to health education. Changes in many sexual practices declined or even reversed trend by 1989 (for example the reduction in teenage attendance and recent partners), despite highly significant downtrends overall. By contrast, the changes in contraceptive practices were all sustained. There may be several reasons for this. The convenience and effectiveness of oral contraception (OC) and intrauterine contraceptive devices (IUCDs) have been offset by a number of factors. IUCDs have been associated with pelvic inflammatory disease (PID) and thus with increased risk of ectopic pregnancy and infertility.$^{89} \mathrm{OC}$ has carried an increased risk of cardiovascular disease ${ }^{10}$ and the threat of breast cancer in younger women. ${ }^{11}$ Neither provide any barrier to STDs. Against this background the looming threat of HIV infection has redirected attention towards barrier contraception, the most effective of which is the condom, as the one form of contraception which can satisfy all three requirements-freedom from unwanted effects, effective contraception and most important of all, protection from sexually transmitted infections, especially HIV.

Case control studies of HIV infection among homosexual men show independent risks from other STDs (especially syphilis and hepatitis B), certain sexual practices (anoreceptive penile intercourse and "fisting") and large numbers of sexual partners (more than 50 in a lifetime). ${ }^{13-15}$ None of these risks is exclusive to homosexual men but our study and that of DeBuono et al, indicate that they are far less frequent among heterosexual women than they are among homosexual men. In our own studies, for example, $65 \%$ of homosexual men reported anoreceptive penile intercourse in 1987 compared with $8 \%$ of heterosexual women and $50 \%$ of homosexual men had had more than 50 lifetime partners compared with $1.4 \%$ of women. 
Anal intercourse seems only of risk to the receptive partner; several studies have shown little or no risk to the insertive partner. ${ }^{13-15}$ Thus the chain of infection can be maintained in homosexual men by role reversal in which a man infected by anoreceptive intercourse may practise penoanal insertion with a subsequent uninfected partner. This cannot occur heterosexually and greatly limits the potential for spread of HIV infection.

The increasing practice of oral intercourse (fellatio), including ejaculation of semen into the mouth, might seem a matter of concern. On the other hand, swallowing of semen by homosexual men showed no correlation with HIV infection on univariate analysis in a previous study $(\mathrm{p}=0 \cdot 2),{ }^{12}$ which suggests that this practice does not constitute a risk.

Non-regular partners are likely to constitute an increased risk of HIV infection and for this reason we examined the sexual practices of women who admitted to non-regular partners (1139) and compared them with women who did not (2060). Despite the obvious risks, the proportion of women reporting non-regular partners remained unchanged over a three year period of intensive public awareness campaigns set up by the Department of Health and continued by the Health Education Authority. Women who had non-regular sexual partners became sexually active about one year earlier but there was no physiological reason for this because menarche occurred slightly later (although not significantly) in the group with non-regular partners. Furthermore, pregnancy was no more likely in this group and thus contraception no less adequate. Although women who reported having non-regular partners might be predicted to have more partners, the difference proved much greater than expected with more than a 14 fold increase in the percentage who reported more than five sexual partners in the past year. Risk of HIV infection was further increased by the more frequent practice of anal intercourse in this group of patients.

The prevalence of HIV infection remained very low $(0.27-0.37 \% ; 95 \%$ CI: $0.09-0.96 \%)$ over the years between 1987 and 1989. This cannot be attributed to changes in sexual behaviour because such a high proportion of women continued to practise risk behaviour and the trend to safer practices was not sustained. It has to be concluded that heterosexual risks have not reached the level necessary for rapid dissemination of HIV infection in the temperate climate of London.

We thank the Virus Reference Laboratory for carrying out the anti-HIV tests; Dr Berge Azadian for transportation of specimens and Sarah Quested for typing the manuscript.

Address correspondence to Dr B A Evans.

1 DeBuono BA, Zinner SH, Daamen M, McCormack WM. Sexual behavior of college women in 1975, 1986 and 1989. $N$ Engl J Med 1990;12:821-5.

2 Evans BA, Bond RA, MacRae KD. Sexual behaviour of women attending a genitourinary medicine clinic. Genitourin Med $1988 ; 64: 43-8$.

3 Evans BA, McCormack SM, Bond RA, MacRae KD, Thorp RW. Human immunodeficiency virus infection, hepatitis $B$ virus infection and sexual behaviour of women attending a genitourinary medicine clinic. $B M J$ 1988;296:473-5.

4 Gill ON, Adler MW, Day NE. Monitoring the prevalence of HIV. BMJ 1989;299:1295-8.

5 Heptonstall J. The legal and ethical basis for unlinked anonymous HIV testing. Communicable Disease Report 89/48 PHLS, London 1989

6 Mortimer PP, Parry JV, Mortimer JY. Which anti-HTLV III/ LAV assays for screening and confirmatory testing? Lancet 1985;ii:873-8.

7 Maxwell AE. Analysing Qualitative Data. London: Chapman and Hall, 1961.

8 Vessey MP, Yeates D, Flavel R, McPherson K. Pelvic inflammatory disease and the intrauterine device findings in a large cohort study. BMJ 1981;282:855-7.

9 Senanayake P, Kramer DG. Contraception and the aetiology of pelvic inflammatory disease. Am J Obstet Gynec 1980;138: 852-60.

10 Cardiovascular disease and the use of oral contraceptives. WHO Collaborative Study. Bull World Health Organ 1989; 67:417-23.

11 Chilvers CE, Deacon JM. Oral contraceptives and breast cancer. Br J Cancer 1990;61:1-4.

12 Evans BA, Dawson SG, McLean KA, et al. Sexual lifestyle and clinical findings related to HTLV III/LAV status in homosexual men. Genitourin Med 1986;62:384-9.

13 Winkelstein W, Lyman DM, Padian N, et al. Sexual practices and risk of infection by the human immunodeficiency virus. The San Francisco men's health study. JAMA 1987;257: 321-5.

14 Kingsley LA, Detels R, Kaslow R, et al. Risk factors for seroconversion to human immunodeficiency virus among male homosexuals. Results from the multicentre AIDS cohort study. Lancet 1987 ;ii:345-9.

15 Evans BA, McLean KA, Dawson SG, et al. Trends in sexual behaviour and risk factors for HIV infection among homosexual men, 1984-7. BMJ 1989;298:215-8.

Accepted for publication 6 February 1991 